\title{
The application of excrement energy engineering in breeding industry
}

\author{
Zheng zhang and Yu-Bo Wang \\ Institute of economics and management, Hubei University of Technology \\ Wuhan, Hubei, China \\ E-mail:51532474@qq.com
}

\begin{abstract}
With the development of intensive animal husbandry, which have brought a lot of problems? The pollution is more and more serious, which has becomes a threat to the agricultural ecology and food safety. At the meanwhile, the pollution seriously affected the healthy development of the breeding industry. In this paper, through cost-benefit method makes an empirical analysis of Deqingyuan biogas power generation project, first of all, it is concluded that intensive farming enterprises can through biogas power generation project on comprehensive utilization of waste circulation agriculture industry chain, realize animal husbandry pollution from "the cure" to " the utilize"; Second, the effectiveness of the processing waste of investment for the livestock industry to provide a testing method; Finally, puts forward several countermeasures and suggestions to intensive aquaculture biogas power generation in breeding industry.
\end{abstract}

Keywords: Biogas Power Generation; Resource Transformation; Circular Economy

\section{Introduction}

In recent years, the animal husbandry of China has developed rapidly, both in the scale and the level. At the same time, the breeding industry has produced a large number of livestock wastes, which brought great pressure on the environment. According to statistics, there is 800 million tons of waste each year in China; animal husbandry pollution problem is serious. Livestock manure has become the main source of agricultural pollution in China [1], but these pollutants are also valuable energy that can be reused. Though the effective treatment and reasonable utilization, we can make waste profitable. Biogas power generation is developed from the comprehensive utilization of biogas engineering, can greatly enhance the technical level of the biogas project. Biogas power generation is an important part of energy engineering, which can solving the problem of pollution and ease the energy shortage. It has been proved that the biogas power generation energy engineering is specialized in environmental protection and energy saving. It's the effective development mode that utilizes livestock and poultry waste in recycle agricultural. 


\section{The Problem of Livestock Waste in China}

Pollution of intensive breeding industry has become the world's common concerned environmental issues. The United States, which $60 \%$ of the rivers are polluted by animal feces. [2, 3]; China produces 3.8 billion tons of livestock and poultry waste every year. In 2014, the large scale livestock breeding discharge of COD and ammonia nitrogen comes by 10.49 million tons and 58 million tons, accounting for $45 \%$ of the national total emissions in 2014 and $25 \%$, accounting for $95 \%$ and $76 \%$ of the total agricultural source pollution [4]. Livestock breeding brings environmental pollution, not only bring great distress to people's life, but also become the important restriction factor that affects the sustainable development of animal husbandry. The animal husbandries goal in " The 13th Five-year " is to make the waste comprehensive utilization rate to $70 \%$ or more, but as far as now the comprehensive utilization still amounted to less than $60 \%$, in order to achieve this goal, we need to find a truly effective treatment of aquaculture waste development path.

\section{Biogas Power Generation the Waste Energy Recycling Operation}

Biogas power generation: through anaerobic fermentation to aquaculture waste into biogas, and then the biogas will be purified to make high quality clean power resources into energy engineering. Biogas power generation projects is not a single method of processing waste, but a combination with energy and fertilizer, it's a complex systems of waste disposal and resource recovery utilization. Regardless of size, a complete biogas power generation projects mostly includes the following process: raw materials (waste) collection, pretreatment, anaerobic digestion system, discharging the post-processing system, biogas purification system, biogas power generation system, electrical and control system, waste heat utilization system, circulating cooling system, mute, etc. Specific implementation process is as follows: after collecting the crop straw and floor waste, farms for stirring mixing pretreatment, then all anaerobic fermentation, produce methane mainly through biogas utilization of biogas power generation; Produce biogas slurry into precipitation filtration, precipitation filtered supernatant fluid into the biogas slurry storage pool used as crop fertilizer or sell output; The renewal to make solid fat, through further processing can be made into organic fertilizer for sale; Heat can give anaerobic fermentation antipyretic or heating farms, through the above ways to realize waste recycling [6]. Biogas power generation process flow diagram, as shown in Figure 1. 


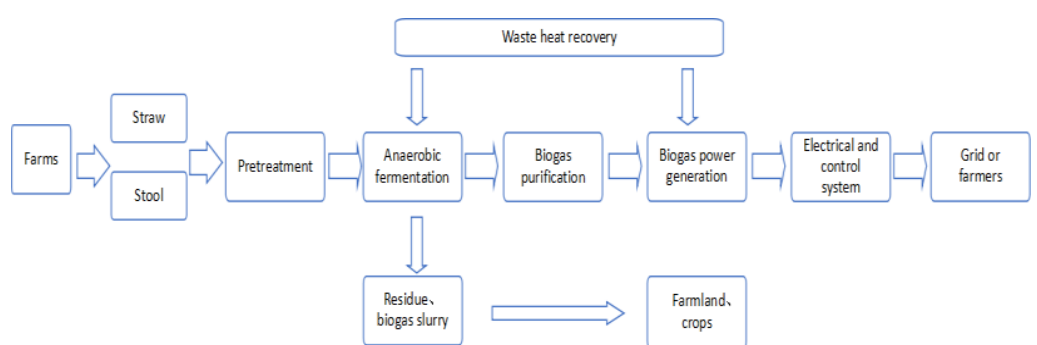

Fig. 1. Flow chart of biogas power generation process.

\section{Problems of Biogas Power Generation Energy Engineering in China}

In recent years, there are a lot of biogas power generation projects in China, but most of them have problems such as costs, electricity acquisition, subsidies, and broken industry chains. First, the biogas power generation costs a lot. Engines and power generation device mostly rely on imports, and they have to build their own grid-connected power transmission and transformation circuit. Even after the power grid was finished, the enterprise needs to pay the fee in transmission line and maintenance. Secondly, the problem of power purchases. Biogas power generation belongs to the distributed generation, capacity is small and not stable, it is too scattered to collect, and biogas power generations cost is higher than thermal, hydraulic, power companies are reluctant to pay a high price to acquire the power of biogas power generation. Third, the subsidy from policies is inadequate. To the cultivation waste processing biogas power generation China do not have a regulation and perk. There is only a general rule of renewable energy power generation. The agriculture and forestry biomass benchmark set grid electricity price is 0.75 yuan/kWh [7]; however it does not include the biogas power generation. Fourth, the industrial chain ruptures. Most commercial enterprise do not have the stable supply of raw materials, renewal biogas slurry have no market in farm, which caused power generation engineering products such as gas, electricity, heat, organic fertilizer did not make full use of, and they can't enter the market, so these products can not reflect its economic value. China does not have such a policy to support the waste reprocessing. To the renewal of biogas slurry utilization and transformation, country do not have a strict standards, which results the agricultural ecosystem is incomplete, the project sustainability is not strong. 


\section{The Empirical Analysis of Biogas Power Generation Applications}

\subsection{Empirical analysis of Beijing Deqing Source 2MV biogas power generation engineering}

Beijing Deqing Source agriculture science and Technology Company is the first company to run biogas power generation project. The company was founded in 2000, started with only hundreds hens, they make hens manure become fertilizer, but the smell of chicken excrement in transit will affect the breeding field air and people's living environment. In 2004, Deqing Source expends their scale to 500000 hens, to solve the problem of pollution, the company collected dung to produce biogas, supply over 200 users electric. In 2006, the company expanded to 3 million hens breeding, the annual output up to 200000 tons of waste, after biogas utilization facilities have been unable to deal with chicken manure, to solve the problem of pollution, the company introduced biogas power generation equipment, realize the grid-connected power generation in 2009, a year to north China electric power with 14 million degree of green power [8]. Because of biogas power generation projects, the company extends its ecological industrial chain. In 2012, Deqing Source will have a renewal of biogas power generation, biogas slurry treated each year about 5500 tons of organic fertilizer, and these organic fertilizer will be sent to farmers, after harvest, farmers will sell corns to Deqing Source. To encourage farmers to use organic fertilizer, Deqing Source punches corns from farmer with a price higher than the market average, thus to guarantee the safety and stability of the feed source. Deqing Source originally in biogas methane content is about $60 \%$, after purification of power concentration above $96 \%$, reach the standard of city gas, this part of the biogas will be used as power of 500 household's farmers. According to the monthly charge 30 yuan per family. Chicken farm will produce two sources: the one is egg, chicken which will be sold in market. The other is dung, which can be used to produce electric power. Generating heat can also give ecology greenhouses heating. The rest of the renewal, biogas slurry and then to recycle. Finally it formed such a result, ecological breeding, food processing, and clean energy - organic fertilizer green organic farming - ecological farming ecological agriculture chain [9]. 
Table 1. Deqing Source biogas power generation energy engineering cost benefit

\begin{tabular}{llll}
\hline index & The specific subjects & $\begin{array}{l}\text { Returns the forehead rate\% } \\
\text { (million) }\end{array}$ & \\
\hline \multirow{4}{*}{ Annual revenue } & Generating income & 882.84 & 45.7 \\
& Organic revenue & 330 & 17.1 \\
& Biogas utilization benefits & 18 & 0.9 \\
& CDM benefits & 700 & 36.3 \\
Total annual revenue & ------ & 1930.84 & 100 \\
\hline \multirow{4}{*}{ Annual cost [10] } & Artificial cost & 36 & 4.1 \\
& Fuel expenditure on power & 100 & 11.3 \\
& The bank loan interest & 135 & 15.2 \\
& annual depreciation & 300 & 33.8 \\
& Equipment maintenance & 30 & 3.4 \\
Total annual cost & For electricity costs & 285 & 32.2 \\
The total investment & ------ & 886 & 100 \\
\hline & Othvestment in transmission line 500 & 7.7 \\
Total investment & ------- & 6000 & 92.3 \\
\hline
\end{tabular}

From Table 1, biogas power generation benefits account for $45.7 \%$ of total revenue, much higher than organic fertilizer, such as methane sales revenue. Biogas power generation cost about 8.86 million yuan, and electricity net income of 8.8284 million yuan, therefore, biogas power generation part of the investment return period for 2 years, visible separate biogas power generation project profit ability is very strong. According to Deqing Source biogas production and power generation, annual export 14 million degrees of electricity to the grid, for 5 million $\mathrm{kWh}$, engineering needs more than six years to fix the cost. For Deqing Source, compared to its main business to the market sales chicken an annual income of 320 million yuan, the biogas power generation revenue is puny, the electric is not the goal, Deqing Source with its biogas power generation to build a chain of ecological agriculture, achieved clean production and animal husbandry production wastes, more industry chain's self-improvement and appreciation, to promote the market competitiveness of the product, the premium for the enterprise. Deqing Source success may be biogas power generation: first, successfully get grid-connected and keep a good cash flow; Secondly catch the opportunity of the clean development mechanism (CDM) projects; Marsh fertilizer on third, resource utilization, the breeding and nearby rural farming together, formed a complete biogas power generation cycle agriculture ecological industry chain.

\subsection{The role of biogas power generation in breeding waste recycling}

For large farms, sewage treatment is the most difficult, now we have the strict 
management to make sure the wastewater discharging. Any farm shall be shut down or even dismantled if it cannot reach the standards. And biogas power generation can make farms wastewater discharge reach the standard, forming a set process to meet the requirements of environmental emissions and emissions of breeding wastewater treatment system. Its low energy consumption, but maximum recycling, it can remove pollution to the surrounding environment and to reduce greenhouse gas emissions, which brought lot environmental benefits. When the large farms processing its waste, if they don't construct the biogas plant, they must also be the construction of large sewage treatment plant to process the waste, it lead to the high investment cost and operation cost, but biogas power generation not only control the pollution and green electricity and renewal biogas slurry can also bring good economic benefits. More important, biogas power generation will be cultivated and combination. To achieve energy efficient transformation between material and efficient circulation, here comes ] the typical cycle agricultural development pattern, which can save resources, reduce pollution, make harm to benefit, promote the livestock farm waste reduction, harmless and recycling, the formation of "planting(feed) - breeding (waste) - methane(electricity, gas) - planting(agricultural products, feed) breeding," the development of circular agriculture ecological industry chain, to the development of the whole society to bring good social benefits.

\section{Suggestions on Promoting the Utilization of Excrement Energy Engineering in Breeding Industry}

Intensive livestock farming could be sustained and healthy development, a clear path is very important. The fact has showed that biogas power generation can promote breeding enterprise to healthy development. Here are some suggestions to the intensive breeding biogas power generation:

First, the farms which have more than 20000 head of cattle, or more than 50000 chicken, pig farms, or one million laying hens can consider taking ecological biogas to generate electricity in order to achieve pollution resource utilization. At the same time, they need to consider the fermentation raw materials, such as the marsh fertilizer supply and demand balance, to avoid resource waste and environmental pollution.

Second, strengthen the development of biogas power generation technology and equipment. One major cause of the high cost of biogas power generation is importing technology and equipment; even they can afford to purchase cost, equipment installation and maintenance, daily operation of the late need technical support. Therefore, the government should be combined with enterprises, scientific research institutions, research and development related equipment production, and provide relevant technical training and research and 
development, improve the domestic biogas power generation technology and equipment innovation and breakthrough, cultivate a group of related professionals.

Third, we should pay attention to the renewal of marsh fertilizer utilization, improve the industrial chain. Renewal marsh fertilizer is a kind of pure natural organic fertilizer, but a large number of biogas slurry were wasted in fact, that caused biogas power generation energy engineering industry chain ruptured. It also hinders the development of biogas power generation industry. The country, the government and enterprises should strengthen the renewal of biogas slurry using the technology and equipment research and development and promotion, increase its utilization in propaganda, encourage farmers to use renewal biogas slurry to produce organic fertilizer, such not only can ensure food safety, make up for the high costs of biogas power generation project, also can realize the continuity of biogas power generation projects.

Fourth, the enterprises should seize opportunity both in international and domestic carbon market. Internationally, we are the sellers of the carbon trading, the domestic many renewable energy applied for CDM project successfully, most of them are wind power, solar power, etc., for livestock and poultry breeding of biogas power generation projects is rare, and agriculture and forestry project is lack of money, as a result, the United Nations EB will focus on agriculture and forestry projects, it contributes to promoting the development of intensive aquaculture biogas power generation. The domestic market, since 2017, our country will build own carbon emissions trading system, biogas power generation has a huge potential to reduce emissions, livestock farming enterprises should actively involve. Therefore, in the future development, intensive farming enterprises should pay special attention to the international and domestic carbon trading in the opportunity.

\section{References}

1. Yuan-yuan Zhou, Yin Jie, Zhi-min Yang, Huang Lei, Chen-yu Cheng. Water environment analysis of Waste of livestock and poultry distribution and response characteristics in Chongqing area, Journal of Chinese ecological agriculture, 2016, 24 (6), pp. 811-818.(In Chinese)

2. Schou J.S., Skop E., Jensen J.D. Integrated agri-environmental modelling: A cost-effectiveness analysis of two nitrogen tax instruments in the Veijle Fjord watershed, Denmark, Journal of Environmental Management, 2000, 58(1), pp. 199-212.

3. Belsky A. JMatzke. A Uselman S Survey of livestock influences on stream and riparian ecosystems in the western United States Journal of Soil and Water Conservation 1999 54(1), pp. 419-431. 
4. Kang-zhen Yu, vice-minister of agriculture in the national standardized scale of livestock and poultry breeding and comprehensive utilization of waste site stressed at the meeting we will promote standardization of large-scale ecological livestock farming Livestock production and environment protection coordination development . Journal of animal husbandry in China, 2015, 21, pp.18.(In Chinese)

5. Yu-e Li, Hong-min Dong, Yun-fan Wan, Xiao-bo Qin, Qing-zhuGao, Hua Luo. Scaly chicken breeding industry CDM project emission reduction and economic benefit estimation, Journal of agricultural engineering, 2009,01, pp. 194-198.(In Chinese)

6. Ning-ning Tian Li Baolin, Kai-jun Wang, Yang Liping. Livestock and poultry breeding industry waste environmental problems and methods of treatment. Journal of environmental protection, 2000, 12, pp. 10 -13.(In Chinese)

7. Of the national development and reform commission notice to perfect the agriculture and forestry biomass price policy [J]. Journal of solar energy, 2010 preceding: 6.(In Chinese)

8. Pan Wenzhi. Large farms methane project - in Beijing, green source of biogas engineering, for example, Journal of China engineering science, 2011, 11, pp. 40-43.(In Chinese)

9. ShuHan. Chicken farms in Deqing Source of "green power", Journal of agricultural engineering, agricultural product processing industry, 2009 practices, pp. 43-45.(In Chinese)

10. Zhu Ning, Ma Ji. Livestock and poultry dung biogas power generation mode development countermeasures study, Journal of resources development and the market, 2014, 01, pp. 38-41.(In Chinese) 